\title{
Diverticular Disease: Reconsidering Conventional Wisdom
}

\author{
Anne F. Peery, MD MSCR ${ }^{1}$ and Robert S. Sandler, MD MPH ${ }^{1}$ \\ ${ }^{1}$ Division of Gastroenterology and Hepatology, Department of Medicine, University of North \\ Carolina School of Medicine, Chapel Hill, NC
}

\section{Abstract}

Colonic diverticula are common in developed countries and complications of colonic diverticulosis are responsible for a significant burden of disease. Several recent publications have called into question long held beliefs about diverticular disease. Contrary to conventional wisdom, studies have not shown that a high fiber diet protects against asymptomatic diverticulosis. The risk of developing diverticulitis among individuals with diverticulosis is lower than the 10-25\% commonly quoted, and may be as low as $1 \%$ over 11 years. Nuts and seeds do not increase the risk of diverticulitis or diverticular bleeding. It is unclear whether diverticulosis, absent diverticulitis or overt colitis, is responsible for chronic gastrointestinal symptoms or worse quality of life. The role of antibiotics in acute diverticulitis has been challenged by a large randomized trial that showed no benefit in selected patients. The decision to perform elective surgery should be made on a case-bycase basis and not routinely after a second episode of diverticulitis, when there has been a complication, or in young people. A colonoscopy should be performed to exclude colon cancer after an attack of acute diverticulitis but may not alter outcomes among individuals who have had a colonoscopy prior to the attack. Given these surprising findings, it is time to reconsider conventional wisdom about diverticular disease.

Colonic diverticulosis is extremely common in developed countries. In a consecutive series of 2000 barium enemas at the Massachusetts General Hospital, approximately two thirds of adults over the age of 85 were found to have colonic diverticula. ${ }^{1}$ More recently, diverticulosis was found in $71 \%$ of colonoscopies in individuals over the age of $80 .{ }^{2}$ Complications of colonic diverticula are responsible for a significant burden of disease. In 2009 , diverticular disease was the $6^{\text {th }}$ most frequent outpatient gastrointestinal diagnosis with 2.6 million clinic visits. ${ }^{3}$ In that same year, diverticular disease was the most common in-patient gastrointestinal diagnosis in the United States with 283,355 hospitalizations at a cost of 2.7 billion dollars. ${ }^{3}$ Almost a quarter (22\%) of patients admitted with diverticulitis underwent urgent or elective surgery for that condition. ${ }^{4}$

Diverticula of the large bowel are out-pouchings in the wall of the colon at weak points in the circular muscle where blood vessels penetrate to supply the mucosa. ${ }^{5}$ Diverticula may be found throughout the colon, but are most common in the sigmoid colon where abnormalities

(C) 2013 The American Gastroenterological Association. Published by Elsevier Inc. All rights reserved.

Corresponding Author: Robert S. Sandler, MD, MPH, Division of Gastroenterology and Hepatology, University of North Carolina School of Medicine, CB\#7555, Chapel Hill, NC 27599-7555, Phone: (919) 966-0090, Fax: (919) 966-9185, rsandler@ med.unc.edu.

Publisher's Disclaimer: This is a PDF file of an unedited manuscript that has been accepted for publication. As a service to our customers we are providing this early version of the manuscript. The manuscript will undergo copyediting, typesetting, and review of the resulting proof before it is published in its final citable form. Please note that during the production process errors may be discovered which could affect the content, and all legal disclaimers that apply to the journal pertain.

Disclosures: None

Author Contributions: AFP - drafting of the manuscript; critical revision of the manuscript for important intellectual content; RSS drafting of the manuscript; critical revision of the manuscript for important intellectual content 
include thickening and elastosis of the teniae, shortening of the bowel, and thickening and folding of the circular muscle. ${ }^{6,7}$ Diverticulosis is most often uncomplicated and asymptomatic. Complications may occur including bleeding, abscess, perforation, fistula, stricture or colitis. The term diverticular disease is generally used to denote diverticulosis with a complication.

Recent reports have challenged long accepted dogma. For example, it is widely believed that diverticulosis is the result of a low fiber diet. ${ }^{8}$ According to conventional wisdom, $10-25 \%$ of patients with colonic diverticula will develop diverticulitis during their lifetime. ${ }^{8}$ Diverticulosis is thought to be associated with chronic gastrointestinal symptoms in the absence of diverticulitis or overt colitis. ${ }^{9}$ Most physicians believe that diverticulitis is an infection and must be treated with antibiotics. ${ }^{10}$ Elective surgical resection of the affected colon has been recommended after a second attack of diverticulitis and after a first attack in young adults to reduce the risk of recurrence. ${ }^{8}$ Colonoscopy is suggested after an episode of acute diverticulitis to exclude colon cancer. ${ }^{8}$

The goal of this paper is to review recent publications that challenge conventional wisdom about diverticular disease.

\section{Fiber}

The hypothesis that diverticulosis is a deficiency disease of Western civilization was made popular by Painter and Burkitt based on their observation that diverticulosis was rare in rural Africa but increasingly common in economically developed countries. ${ }^{11,12}$ They attributed the difference in disease prevalence to differences in dietary fiber. They presumed that the rural African diet was high in dietary fiber and that economically developed countries consumed a low fiber diet. They proposed that this deficiency of fiber predisposed to diverticulosis. Neither diet nor diverticulosis was actually measured in their studies and they did not account for important potentially confounding variables such as age and sex.

Painter and Burkitt proposed that the deficiency of fiber led to constipation and high pressure segmentation of the colon that resulted in mucosal herniation through weak sections of the colon wall. To support their hypothesis they conducted motility studies that compared intracolonic pressures in patients with diverticulosis to intracolonic pressures in controls. ${ }^{13}$ While they reported that patients with diverticulosis had higher colonic pressures, the authors only reported pressure measurements for select cases and there were no statistical analyses. Motility studies of the colon have not consistently demonstrated that patients with diverticulosis have elevated colonic pressures. ${ }^{14-19}$ Along the same lines, Painter and Burkitt conducted colonic transit studies and found that a population consuming a Western diet had longer mean colonic transit times and lower mean stool weights compared with an African population. ${ }^{20}$ Studies in populations with colonic diverticula, on the other hand, have demonstrated shorter colonic transit times compared with controls. ${ }^{21,22}$

The fiber hypothesis is extremely popular. The concept of forceful contractions of the colon leading to herniation makes sense. However, the hypothesis has persisted for four decades largely without proof. Historically it has been a challenge to refute the hypothesis because a proper study would require a structural exam (e.g. barium enema) in asymptomatic individuals to document the presence of diverticula. With the widespread use of screening colonoscopy we now have the opportunity to study large numbers of people who are undergoing a structural exam of their colon in the absence of symptoms.

We recently published a colonoscopy-based cross-sectional study of dietary risk factors for diverticulosis. ${ }^{23}$ Each of the 2104 subjects had a colonoscopy to the cecum between 1998 and 2010. Participants completed a telephone interview that included a comprehensive 
semiquantitative food frequency questionnaire as well as questions about bowel frequency and physical activity. Contrary to expectation, we found that a high-fiber diet was associated with a higher (not lower) prevalence of diverticula. ${ }^{23}$ The association with dietary fiber intake was dose-dependent and stronger when limited to cases with multiple diverticula. We also found that constipation was not a risk factor for diverticulosis. Instead, we found that participants who had regular bowel movements (7 bowel movements per week) had a $34 \%$ higher risk of diverticulosis compared to participants who had less frequent bowel movements ( $<7$ bowel movement per week).

Study participants were interviewed after their colonoscopy and were aware, in most cases, that diverticulosis had been found. In response to the concern that the study may have been susceptible to response bias and reverse causality from the subjects' knowledge of their diagnoses, ${ }^{24}$ we performed a second cross sectional study in a different population where we limited the analysis to participants with no knowledge of their diverticulosis status. The second study confirmed the results of the initial work. [unpublished] Similar results with respect to fiber were found in two colonoscopy based studies in non-Western populations, although diverticula in Asia are predominantly found in the right colon and may have a different etiology. 25,26

While recent studies suggest that a high fiber diet does not protect against the development of diverticulosis ${ }^{23}$ there is some evidence that a high fiber diet may protect against diverticular disease. Crowe et al studied 47,033 men and women in England and Scotland. ${ }^{27}$ Individuals who reported consuming a vegetarian diet had a lower risk of admission to the hospital or death from diverticular disease. There was also an inverse association for fiber intake. Those in the highest quintile of fiber consumption were $41 \%$ less likely to have a complication from diverticular disease. Similar results were seen in a prospective study of US male health professionals. ${ }^{28}$

It is important to recognize that the research to date was designed to improve our understanding of risk factors for diverticulosis and its complications and not to make dietary recommendations. There are advantages to eating a high fiber, plant-based diet with respect to constipation, heart disease and cancer. ${ }^{29,30}$

\section{Risk of Diverticulitis}

It is generally reported that $10-25 \%$ of patients with diverticulosis will develop diverticulitis during their lifetime. ${ }^{31}$ This estimate is based on a widely cited review of the natural history of diverticular disease published by Parks in $1975 .{ }^{32}$ The largest case series, published almost three decades earlier in 1947, included 47,000 roentgenologic examinations of the colon. ${ }^{33}$ Diverticulosis was diagnosed in $8.5 \%$ of the exams. Of the patients with diverticulosis, $15 \%$ were diagnosed with diverticulitis. Because the study did not include any formal description of the methods, the indication for the original roentgenologic exam and the criteria for a diagnosis of diverticulitis are unknown. A 1958 case series described the natural history of diverticulosis in 300 patients diagnosed with diverticulosis by doublecontrast barium enema. ${ }^{34} \mathrm{~A}$ diagnosis of diverticulitis was made for patients who subsequently presented with acute constipation or diarrhea, abdominal cramping, localized tenderness, fever and leukocytosis. In that study, $10 \%$ of patients with diverticulosis developed diverticulitis over a follow up period of one to five years. Among those followed for six to ten years, $25 \%$ developed diverticulitis. Smaller case series have also reported estimates of the risk of developing diverticular disease in those with diverticulosis. ${ }^{35}$

In order to accurately calculate the cumulative incidence of diverticulitis it would be necessary to enroll a population of patients with diverticulosis and no history of diverticulitis. These individuals would then be observed over time for the development of 
diverticulitis. The widely quoted estimates are based on studies that were done more than 50 years ago and that were potentially biased. The studies began with patients who sought medical care and subsequently received a diagnosis of diverticulosis. This approach selects for a population more likely to have diverticular disease and thus likely overestimates the risk of diverticulitis. Furthermore, these studies only included patients who followed up in subsequent visits. Patients with diverticulosis without any symptoms were less likely to follow up.

Recent data suggest that the lifetime risk of diverticulitis is lower than commonly cited. Spiegel et al. ${ }^{36}$ estimated the incidence of acute diverticulitis in a retrospective cohort of Veterans with diverticulosis incidentally found on colonoscopy. The risk of diverticulitis confirmed by CT scan or surgery was $1 \%$ over 11 years of follow up.

With the widespread use of colonoscopy for screening for colorectal cancer, many patients are being given a diagnosis of diverticulosis and then warned that their risk of a complication is 1 in 4 . This prediction appears to be exaggerated.

\section{Nuts and Seeds}

For more than fifty years, patients with diverticulosis were advised to avoid foods that may leave coarse particulate in the stool, i.e. nuts, corns and seeds. ${ }^{10,34,37}$ This recommendation was based on the hypothesis that these particles might obstruct a narrow-necked diverticulum or physically abrade a diverticulum thereby initiating a cascade of events resulting in diverticulitis or diverticular hemorrhage. In a landmark study, Strate et al ${ }^{38}$ found that dietary nuts, corn and seeds were not associated with an increased risk of diverticulitis or diverticular bleeding in a prospective cohort of male health professionals.

\section{Chronic Symptoms}

A recent taxonomy of diverticular disease terms distinguishes several types of symptomatic disease. ${ }^{9}$ The taxonomy includes two types of chronic diverticulitis - chronic recurrent diverticulitis and segmental colitis associated with diverticulosis. ${ }^{9}$ Chronic recurrent diverticulitis may begin early after the initial episode, and may be consistent with failure of the index episode to 'settle'. ${ }^{39}$ Segmental colitis associated with diverticulosis is defined as peri-diverticular colitis that spares the rectum. ${ }^{9}$ It is not surprising that patients with chronic recurrent diverticulitis and segmental colitis associated with diverticulosis have symptoms given their measurable colonic inflammation. Another category of chronic disease has been termed symptomatic uncomplicated diverticular disease (SUDD) and is defined as diverticulosis associated with chronic gastrointestinal symptoms in the absence of diverticulitis or overt colitis. ${ }^{9}$ The criteria for a diagnosis of symptomatic uncomplicated diverticular disease do not include a history of acute diverticulitis.

The literature on symptomatic uncomplicated diverticular disease is limited and confusing. For example, a small Italian study administered a general quality of life survey (Short Form 36) to 58 outpatients who met criteria for symptomatic uncomplicated diverticular disease and had symptoms of abdominal pain/discomfort, bloating, tenesmus, diarrhea, abdominal tenderness, fever or dysuria. ${ }^{40}$ Not surprisingly, the quality of life scores were lower than a normative Italian population at baseline. It is not possible to conclude that either the symptoms or the decrement in quality of life were due to diverticulosis. At six months, quality of life scores had improved suggesting that the initial low scores were due to diverticulitis or other acute illness at baseline. In another study, 12 patients with symptomatic uncomplicated diverticular disease were compared to 13 controls. The diverticular disease patients were found to have visceral hypersensitivity based on rectal 
barostat studies perhaps mediated by ongoing inflammation and upregulation of tachykinins based on colonic histology. 41

In contrast, a study of 784 subjects who had a structural examination of their colon found that the frequency of abdominal pain, diarrhea, constipation and irritable bowel was similar in patients with and without diverticulosis. ${ }^{42}$ The study used Rome criteria for IBS to classify patients and the response rates were high. Subjects completed questionnaires prior to structural exams. This study casts doubt on whether diverticulosis is associated with chronic symptoms.

Symptomatic uncomplicated diverticular disease may simply be irritable bowel syndrome in patients who are found to have diverticulosis because they undergo colonoscopy. A population-based, cross-sectional study found an increased risk for colonic diverticulosis among patients with irritable bowel syndrome compared to those without. ${ }^{43}$ Whether IBS and diverticular disease share an underlying pathophysiology or whether patients with IBS symptoms are simply more likely to undergo structural exams that reveal diverticulosis is uncertain.

Some patients appear to have chronic abdominal pain after a bout of diverticulitis. This postdiverticulitis irritable bowel syndrome may be akin to the IBS that develops after an acute bowel infection (post-infectious IBS) and would seem more appropriately considered a form of IBS rather than a type of chronic diverticular disease.

In summary, it is unclear whether diverticulosis, in the absence of diverticulitis or overt inflammation is responsible for chronic gastrointestinal symptoms or decreased quality of life. The prevalence of diverticulosis approaches $80 \%$ in 80 year olds. The vast majority of those individuals do not have symptoms. We need more research to identify the subset that has symptoms and to determine why.

\section{The Role of Antibiotics in Diverticulitis}

A 2007 New England Journal of Medicine review on diverticulitis recommended that mild attacks of acute diverticulitis should be treated with 7 to 10 days of oral broad-spectrum antibiotics. ${ }^{10}$ The review noted that the pathogenesis of diverticulitis is unknown but restated the common hypothesis that diverticulitis is the result of an obstruction at the neck of the diverticulum, mucosal abrasion, low grade inflammation and bacterial translocation. Mild diverticulitis is thought to be a micro perforation and more severe disease, gross perforation. In short, all manifestations of diverticulitis have been presumed to be due to infection that should be treated with antibiotics.

A recent multicenter randomized controlled trial in Sweden and Iceland recruited 623 patients who had typical symptoms, uncomplicated left-sided diverticulitis documented by CT scan, and a temperature above $38^{\circ} \mathrm{C} .{ }^{44}$ Subjects were excluded if they had an abscess, fistula or free air on CT or if they had high fever, peritonitis or sepsis. Subjects were randomized to broad-spectrum antibiotics or IV fluids without antibiotics. Despite randomization, the groups were not completely balanced with more episodes of prior diverticulitis in the antibiotic group (44.8\%) compared to the non antibiotic group (35.6\%) $(\mathrm{p}=-0.02)$. During the first 5 days following admission there were no differences in abdominal pain, temperature or abdominal tenderness. There was no difference in mean hospital stay, complications (perforation or abscess) or recurrent diverticulitis necessitating readmission to the hospital during the first year. In the group randomized to no antibiotics only $3(1 \%)$ developed an abscess compared to no cases in the antibiotic group $(\mathrm{p}=0.08)$ The authors concluded that antibiotics should be used only in cases of complicated diverticulitis. ${ }^{44}$ Danish national guidelines for treatment of diverticular disease do not 
recommend antibiotics for the treatment of uncomplicated diverticulitis (grade A). ${ }^{45}$ The guidelines support the use of antibiotics for the treatment of uncomplicated diverticulitis if the patient is septic, pregnant or immunosuppressed based on limited data (grade C). ${ }^{45}$

The strong evidence from a large randomized controlled trial showing no benefit of antibiotics in uncomplicated diverticulitis raises important questions about etiology and management of diverticulitis. ${ }^{46}$ Acute diverticulitis may be an inflammatory rather than an infectious condition. ${ }^{47}$ There has been the recent recognition of a form of segmental colitis associated with diverticular disease that mimics chronic idiopathic inflammatory bowel disease histologically. ${ }^{48}$ Although this entity is not common ${ }^{49}$, it might explain some cases of diverticulitis that improve without antibiotics.

\section{Elective Surgery}

Guidelines for the diagnosis and management of diverticular disease of the colon in adults published in 1999 state that elective (prophylactic) surgery may be reasonable in patients with recurrent attacks of diverticulitis. ${ }^{8}$ The recommendation was based on the fact that the risk of recurrent symptoms after an attack of acute diverticulitis ranged from $7 \%$ to $62 \%$ and because recurrent attacks were less likely to respond to medical therapy and have higher mortality. The guidelines suggested that the approach should be individualized based on the severity and responsiveness of the attack, general health of the patient and the risk of surgery compared to the risk of a future attack.

More recent studies of the natural history of acute diverticulitis, on the other hand, suggest that medically managed acute diverticulitis has a low recurrence rate and rarely progresses to complications. In one retrospective cohort study, the risk of recurrent acute diverticulitis after an initial episode of medically managed acute diverticulitis was $13 \%$ over 9 years. ${ }^{50} \mathrm{~A}$ second retrospective cohort found that the risk of recurrent acute diverticulitis was $19 \%$ over 16 years. ${ }^{51}$ A study published in 2010 found that $23 \%$ of patient had a recurrence. ${ }^{39}$ Most had a single recurrence with only $4.7 \%$ having more than two episodes of diverticulitis.

After an initial episode of uncomplicated acute diverticulitis, the risk of complicated disease was $5 \%$ over 8 years. ${ }^{39}$ The risk of recurrence was no greater in complicated disease (abscess, stricture, fistula) than uncomplicated disease suggesting the elective surgery should not be routinely recommended for complicated disease.

Janes et al ${ }^{52}$ calculated that the risk of an individual requiring an urgent operation was 1 in 2000 patient-years of follow-up. They further noted that there was a high complication rate in surgery for diverticular disease and that $27-33 \%$ of patients had ongoing symptoms after bowel resection, not necessarily attributed to recurrent acute diverticulitis.

The more widespread use of laparoscopic resection might be expected to decrease the operative risk for elective colectomy. We still must balance the risk of surgery with the risk of a complicated future attack of diverticulitis. The American Society of Colon and Rectal Surgeons has appropriately recommended consideration of elective sigmoid colectomy after recovery from acute diverticulitis on a case-by-case basis with the decision based on the age, co-morbid disease, the frequency and severity of the attacks, and whether symptoms persist after the acute episode. ${ }^{53}$

\section{Diverticulitis in Younger Patients}

Diverticulitis is thought to be more virulent in younger patients with $25-80 \%$ reportedly requiring urgent surgery during their initial attack. ${ }^{28,54-58}$ The recurrence rate has also been reported to be higher in younger patients in older studies. ${ }^{59-62}$ American College of Gastroenterology practice guidelines for diverticular disease state that elective 
(prophylactic) surgery after one episode of uncomplicated diverticulitis may be reasonably considered in younger patients based on both the low operative risk of an elective procedure in a healthy young person and the many years of future risk of recurrence. ${ }^{8}$

More recent studies have challenged the view that diverticulitis is more virulent in younger patients and the recommendation for surgical intervention after an initial event. ${ }^{51}$ Anaya et $\mathrm{al}^{51}$ found that while there was an increased relative risk for emergency colectomy or colostomy in younger patients, the absolute risk was low. These authors found that $73 \%$ of younger patients had no recurrence and most resolved without surgery. Their work demonstrated that a policy of routine elective colectomy in a younger population would require 13 elective operations to prevent 1 emergency colectomy.

\section{Colonoscopy}

The American College of Gastroenterology guidelines recommend colonic evaluation after resolution of clinically diagnosed diverticulitis to exclude other diagnostic considerations, particularly cancer. ${ }^{8}$ Because of the potential for perforation due to the microabscess that presumably caused acute diverticulitis, the examination is typically postponed for at least 6 weeks.

There is an increased risk of colon cancer in the first year after a diagnosis of diverticular disease. A population-based case control study of 41,037 patients with colon cancer found an increased odds (OR 25, CI 17-38) of a colon cancer diagnosis within 6 months of an admission for diverticular disease. There was no association with a colon cancer diagnosis 12 months after the admission for diverticular disease. The increased risk of colon cancer within 12 months of an admission for diverticular disease was attributed to surveillance bias and misclassification. ${ }^{63}$

If a patient has had a recent colonoscopy prior to developing acute diverticulitis, whether there is any utility in a repeat endoscopic exam is unknown. Lau et $\mathrm{al}^{64}$ found a number of cancers and other significant lesions when they performed colonoscopy after an acute attack of diverticulitis. However, they excluded patients who had a colonoscopy within a year, and therefore recommended only performing colonoscopic exams for individuals who had not had a recent radiologic or endoscopic colonic exam.

A colonoscopy should be performed to exclude colon cancer after an initial episode of suspected diverticulitis. If a patient has had a recent colonoscopy prior to developing acute diverticulitis, the value of a repeat colonoscopy to exclude cancer is unknown.

\section{Conclusions}

Recent work in diverticulosis has created uncertainty among both researchers and clinicians. The theories of prior generations have been proven to be questionable and in some cases unsupportable. A high fiber diet may not protect against asymptomatic diverticulosis. The risk of developing diverticulitis is likely a fraction of the 10-25\% commonly quoted. Nuts and seeds do not increase the risk of diverticulitis or diverticular bleeding. The decision to perform elective surgery after surgical management of acute diverticulitis should be made on a case-by-case basis. A colonoscopy should be performed to exclude colon cancer after an attack of acute diverticulitis but may not alter outcomes among individuals who have had a colonoscopy prior to the attack.

A number of important questions remain. What is the mechanism of diverticular disease? Is there an important component of infection, or is diverticulitis something else entirely? Are there high-risk patients who should undergo early elective surgery? Are there diets that truly 
prevent diverticular disease? We know so little, but at least we are starting to ask the right questions.

\section{Acknowledgments}

Grant Support: This publication was supported by grants from the National Institutes of Health (R01 DK094738 and T32 DK07634)

\section{References}

1. Welch CE, Allen AW, Donaldson GA. An appraisal of resection of the colon for diverticulitis of the sigmoid. Ann Surg. 1953; 138(3):332-343. [PubMed: 13080959]

2. Everhart JE, Ruhl CE. Burden of digestive diseases in the United States part II: lower gastrointestinal diseases. Gastroenterology. 2009; 136(3):741-754. [PubMed: 19166855]

3. Peery AF, Dellon ES, Lund J, et al. Burden of gastrointestinal disease in the United States: 2012 update. Gastroenterology. 2012; 143(5):1179-1187. [PubMed: 22885331]

4. Masoomi H, Buchberg BS, Magno C, et al. Trends in diverticulitis management in the United States from 2002 to 2007. Arch Surg. 2011; 146(4):400-406. [PubMed: 21173283]

5. Slack WW. The anatomy, pathology, and some clinical features of divericulitis of the colon. Br J Surg. 1962; 50:185-190. [PubMed: 13913774]

6. Hughes LE. Postmortem survey of diverticular disease of the colon. I. Diverticulosis and diverticulitis. Gut. 1969; 10(5):336-344. [PubMed: 5771665]

7. Hughes LE. Postmortem survey of diverticular disease of the colon. II. The muscular abnormality of the sigmoid colon. Gut. 1969; 10(5):344-351. [PubMed: 5771666]

8. Stollman NH, Raskin JB. Diagnosis and management of diverticular disease of the colon in adults. Ad Hoc Practice Parameters Committee of the American College of Gastroenterology. Am J Gastroenterol. 1999; 94(11):3110-3121. [PubMed: 10566700]

9. Strate LL, Modi R, Cohen E, et al. Diverticular disease as a chronic illness: evolving epidemiologic and clinical insights. Am J Gastroenterol. 2012; 107(10):1486-1493. [PubMed: 22777341]

10. Jacobs DO. Clinical practice. Diverticulitis. N Engl J Med. 2007; 357(20):2057-2066. [PubMed: 18003962]

11. Painter NS. Diverticular disease of the colon--a disease of the century. Lancet. 1969; 2(7620):586588. [PubMed: 4186011]

12. Painter NS, Burkitt DP. Diverticular disease of the colon: a deficiency disease of Western civilization. Br Med J. 1971; 2(5759):450-454. [PubMed: 4930390]

13. Painter NS, Truelove SC, Ardran GM, et al. Segmentation and the Localization of Intraluminal Pressures in the Human Colon, with Special Reference to the Pathogenesis of Colonic Diverticula. Gastroenterology. 1965; 49:169-177. [PubMed: 14323727]

14. Bassotti G, Battaglia E, Spinozzi F, et al. Twenty-four hour recordings of colonic motility in patients with diverticular disease: evidence for abnormal motility and propulsive activity. Dis Colon Rectum. 2001; 44(12):1814-1820. [PubMed: 11742167]

15. Parks TG, Connell AM. Motility studies in diverticular disease of the colon. Gut. 1969; 10(7):534542. [PubMed: 5806933]

16. Weinreich J, Andersen D. Intraluminal pressure in the sigmoid colon. II. Patients with sigmoid diverticula and related conditions. Scand J Gastroenterol. 1976; 11(6):581-586. [PubMed: 981962]

17. Weinreich J, Moller SH, Andersen D. Colonic haustral pattern in relation to pressure activity and presence of diverticula. Scand J Gastroenterol. 1977; 12(7):857-864. [PubMed: 594654]

18. Leandro PA, Cecconello I, Habr-Gama A, et al. Gastrointestinal motility in normal subjects and patients with diverticulosis of the colon. Arq Gastroenterol. 1984; 21(4):157-163. [PubMed: 6536253]

19. Viebig RG, Pontes JF, Michelsohn NH. Electromanometry of the rectosigmoid in colonic diverticulosis. Arq Gastroenterol. 1994; 31(4):135-144. [PubMed: 7575173] 
20. Burkitt DP, Walker AR, Painter NS. Effect of dietary fibre on stools and the transit-times, and its role in the causation of disease. Lancet. 1972; 2(7792):1408-1412. [PubMed: 4118696]

21. Manousos ON, Truelove SC, Lumsden K. Transit times of food in patients with diverticulosis or irritable colon syndrome and normal subjects. Br Med J. 1967; 3(5568):760-762. [PubMed: 4962724]

22. Kirwan WO, Smith AN. Colonic propulsion in diverticular disease, idiopathic constipation, and the irritable colon syndrome. Scand J Gastroenterol. 1977; 12(3):331-335. [PubMed: 866996]

23. Peery AF, Barrett PR, Park D, et al. A high-fiber diet does not protect against asymptomatic diverticulosis. Gastroenterology. 2012; 142(2):266-272. [PubMed: 22062360]

24. Strate LL. Diverticulosis and dietary fiber: rethinking the relationship. Gastroenterology. 2012; 142(2):205-207. [PubMed: 22185897]

25. Song JH, Kim YS, Lee JH, et al. Clinical characteristics of colonic diverticulosis in Korea: a prospective study. Korean J Intern Med. 2010; 25(2):140-146. [PubMed: 20526386]

26. Lin OS, Soon MS, Wu SS, et al. Dietary habits and right-sided colonic diverticulosis. Dis Colon Rectum. 2000; 43(10):1412-1418. [PubMed: 11052519]

27. Crowe FL, Appleby PN, Allen NE, et al. Diet and risk of diverticular disease in Oxford cohort of European Prospective Investigation into Cancer and Nutrition (EPIC): prospective study of British vegetarians and non-vegetarians. BMJ. 2011; 343:d4131. [PubMed: 21771850]

28. Aldoori WH, Giovannucci EL, Rockett HR, et al. A prospective study of dietary fiber types and symptomatic diverticular disease in men. J Nutr. 1998; 128(4):714-719. [PubMed: 9521633]

29. Anderson JW, Baird P, Davis RH Jr, et al. Health benefits of dietary fiber. Nutr Rev. 2009; 67(4): 188-205. [PubMed: 19335713]

30. Aune D, Chan DS, Lau R, et al. Dietary fibre, whole grains, and risk of colorectal cancer: systematic review and dose-response meta-analysis of prospective studies. BMJ. 2011; 343:d6617. [PubMed: 22074852]

31. Stollman N, Raskin JB. Diverticular disease of the colon. Lancet. 2004; 363(9409):631-639. [PubMed: 14987890]

32. Parks TG. Natural history of diverticular disease of the colon. Clin Gastroenterol. 1975; 4(1):5369. [PubMed: 1109820]

33. Pemberton JD, Black BM, Maino CR. Progress in the surgical management of diverticulitis of the sigmoid colon. Surg Gynecol Obstet. 1947; 85(4):523-534. [PubMed: 20264336]

34. Horner JL. Natural history of diverticulosis of the colon. Am J Dig Dis. 1958; 3(5):343-350. [PubMed: 13520671]

35. Boles RS Jr, Jordan SM. The clinical significance of diverticulosis. Gastroenterology. 1958; 35(6): 579-582. [PubMed: 13609810]

36. Shahedi KFG, Bolus R, et al. Progression from incidental diverticulosis to acute diverticulitis. Gastroenterology May. 2012; 142(5 Supplement 1):S144-S.

37. Salzman H, Lillie D. Diverticular disease: diagnosis and treatment. Am Fam Physician. 2005; 72(7):1229-1234. [PubMed: 16225025]

38. Strate LL, Liu YL, Syngal S, et al. Nut, corn, and popcorn consumption and the incidence of diverticular disease. JAMA. 2008; 300(8):907-914. [PubMed: 18728264]

39. Eglinton T, Nguyen T, Raniga $S$, et al. Patterns of recurrence in patients with acute diverticulitis. Br J Surg. 2010; 97(6):952-957. [PubMed: 20474006]

40. Comparato G, Fanigliulo L, Aragona G, et al. Quality of life in uncomplicated symptomatic diverticular disease: is it another good reason for treatment? Dig Dis. 2007; 25(3):252-259. [PubMed: 17827951]

41. Humes DJ, Simpson J, Smith J, et al. Visceral hypersensitivity in symptomatic diverticular disease and the role of neuropeptides and low grade inflammation. Neurogastroenterol Motil. 2012; 24(4): 318-e163. [PubMed: 22276853]

42. Kang JY, Firwana B, Green AE, et al. Uncomplicated diverticular disease is not a common cause of colonic symptoms. Aliment Pharmacol Ther. 2011; 33(4):487-494. [PubMed: 21158878] 
43. Jung HK, Choung RS, Locke GR 3rd, et al. Diarrhea-predominant irritable bowel syndrome is associated with diverticular disease: a population-based study. Am J Gastroenterol. 2010; 105(3): 652-661. [PubMed: 19861955]

44. Chabok A, Pahlman L, Hjern F, et al. Randomized clinical trial of antibiotics in acute uncomplicated diverticulitis. Br J Surg. 2012; 99(4):532-539. [PubMed: 22290281]

45. Andersen JC, Bundgaard L, Elbrond H, et al. Danish national guidelines for treatment of diverticular disease. Dan Med J. 2012; 59(5):C4453. [PubMed: 22549495]

46. Westwood DA, Eglinton TW. Antibiotics may not improve short-term or long-term outcomes in acute uncomplicated diverticulitis. Evid Based Med. 2013; 18(1):32-33. [PubMed: 22723593]

47. Gatta L, Vakil N, Vaira D, et al. Efficacy of 5-ASA in the treatment of colonic diverticular disease. J Clin Gastroenterol. 2010; 44(2):113-119. [PubMed: 19561530]

48. Lamps LW, Knapple WL. Diverticular disease-associated segmental colitis. Clin Gastroenterol Hepatol. 2007; 5(1):27-31. [PubMed: 17234553]

49. Tursi A, Elisei W, Giorgetti GM, et al. Inflammatory manifestations at colonoscopy in patients with colonic diverticular disease. Aliment Pharmacol Ther. 2011; 33(3):358-365. [PubMed: 21133960]

50. Broderick-Villa G, Burchette RJ, Collins JC, et al. Hospitalization for acute diverticulitis does not mandate routine elective colectomy. Arch Surg. 2005; 140(6):576-581. discussion 81-3. [PubMed: 15967905]

51. Anaya DA, Flum DR. Risk of emergency colectomy and colostomy in patients with diverticular disease. Arch Surg. 2005; 140(7):681-685. [PubMed: 16027334]

52. Janes S, Meagher A, Frizelle FA. Elective surgery after acute diverticulitis. Br J Surg. 2005; 92(2): 133-142. [PubMed: 15685694]

53. Rafferty J, Shellito P, Hyman NH, et al. Practice parameters for sigmoid diverticulitis. Dis Colon Rectum. 2006; 49(7):939-944. [PubMed: 16741596]

54. Freischlag J, Bennion RS, Thompson JE Jr. Complications of diverticular disease of the colon in young people. Dis Colon Rectum. 1986; 29(10):639-643. [PubMed: 3757703]

55. Chautems RC, Ambrosetti P, Ludwig A, et al. Long-term follow-up after first acute episode of sigmoid diverticulitis: is surgery mandatory?: a prospective study of 118 patients. Dis Colon Rectum. 2002; 45(7):962-966. [PubMed: 12130887]

56. Reisman Y, Ziv Y, Kravrovitc D, et al. Diverticulitis: the effect of age and location on the course of disease. Int J Colorectal Dis. 1999; 14(4-5):250-254. [PubMed: 10647635]

57. Spivak H, Weinrauch S, Harvey JC, et al. Acute colonic diverticulitis in the young. Dis Colon Rectum. 1997; 40(5):570-574. [PubMed: 9152186]

58. Konvolinka CW. Acute diverticulitis under age forty. Am J Surg. 1994; 167(6):562-565. [PubMed: 8209928]

59. Eusebio EB, Eisenberg MM. Natural history of diverticular disease of the colon in young patients. Am J Surg. 1973; 125(3):308-311. [PubMed: 4690116]

60. Ambrosetti P, Robert JH, Witzig JA, et al. Acute left colonic diverticulitis in young patients. J Am Coll Surg. 1994; 179(2):156-160. [PubMed: 8044384]

61. Ouriel K, Schwartz SI. Diverticular disease in the young patient. Surg Gynecol Obstet. 1983; 156(1):1-5. [PubMed: 6600202]

62. McConnell EJ, Tessier DJ, Wolff BG. Population-based incidence of complicated diverticular disease of the sigmoid colon based on gender and age. Dis Colon Rectum. 2003; 46(8):1110-1114. [PubMed: 12907908]

63. Granlund J, Svensson T, Granath F, et al. Diverticular disease and the risk of colon cancer - a population-based case-control study. Aliment Pharmacol Ther. 2011; 34(6):675-681. [PubMed: 21790681]

64. Lau KC, Spilsbury K, Farooque Y, et al. Is colonoscopy still mandatory after a CT diagnosis of left-sided diverticulitis: can colorectal cancer be confidently excluded? Dis Colon Rectum. 2011; 54(10):1265-1270. [PubMed: 21904141] 